\title{
Entrevista sobre Filosofia Africana com o professor Dr. Dimas A. Masolo
}

\author{
SERGIO LUIS DO NASCIMENTOa \\ DAVIDE SCARSO
}

\section{Apresentação}

Tivemos o privilégio de conhecer o Prof. Dismas A. Masolo durante as atividades da segunda edição do Anthropocene, em 2018. A partir de uma conversa informal surgiu a ideia de uma entrevista, que se realizou por via telefônica no ano seguinte, agora publicada em tradução portuguesa. O Prof. Masolo nasceu e passou parte da sua vida no Quênia sob dominação colonial britânica, obteve o doutorado em Filosofia pela Università Gregoriana (Itália) e lecionou em várias universidades n África e nos Estados Unidos da América. Hoje, é professor de filosofia na University of Louisville (EUA) e uma das principais referências internacionais na área da Filosofia Africana. Entre as suas publicações vale a pena mencionar Self and community in a Changing World (2010) e African Philosophy in Search of Identity (com I. Karp, 2000). A entrevista aborda tanto de um ponto de vista da afrocentricidade e da ancestraliade epistemilógico, como da perspectiva para o ensino dispórico. As perguntas foram provocadas pelo Grupo de Estudos Relações Étnicorraciais.

\footnotetext{
a Pontifícia Universidade Católica do Paraná (PUCPR), Curitiba, PR, Brasil. Doutor em Educação e-mail: axesergio@yahoo.com.br b Universidade de Lisboa (UL), Lisboa, Portugal. Doutor em Filosofia, e-mail: davidescarso@gmail.com
} 


\section{1) Tendo em consideração a dimensão e a diversidade do continente africano,} com mais de cinquenta países diferentes, quando falamos de Filosofia Africana há um risco de homogeneização?

Quando as pessoas pensam em algo comum que as possam unir nas suas lutas e nas suas esperanças, de um ponto de vista histórico, há sempre tendência a pensar na homogeneidade das diferentes vozes que as constituem. Nesse sentido, a África não foi exceção. A descolonização, a libertação, são questões que uniram muitos povos africanos, uniram muitas pessoas que eram colonizadas ou reprimidas em formas diferentes. Uniram as pessoas de uma forma tal que isso deu a impressão de que o continente fosse homogêneo, de que houvesse apenas uma única África. O que, em termos de estratégia política, foi útil para conseguir a liberdade face ao colonizador, mas isso não diminui o fato de que a África é muito diferenciada, e não apenas em termos de aspirações nacionais. As pessoas lutaram para a descolonização e para se tornar nações independentes com objetivos muito específicos, vistos do ponto de vista da natureza da luta que foi específica a cada país. Mas, além disso, a África é um lugar com mais de 600 comunidades étnicas, cada uma com sua cultura autônoma. Tendo isso tudo em conta, nenhum de nós pode ignorar, e não deve ignorar, a diversidade que a África possui, e que sua diversidade é um valor, uma preciosidade que a África deve assumir e continuar a desenvolver e apoiar. Porque nos dá perspectivas diferentes de pontos de vista culturais diferentes, e isso é algo que devemos celebrar. No primeiro período da Filosofia Africana, sob o fardo da descolonização, houve tendência a defender uma perspectiva política que via a África como unitária e não diferenciada. Alguns filósofos, trabalhando nessas condições, tenderam a ver a Filosofia Africana de forma demasiado generalizante. Por outro lado, poder-se-ia também dizer que eles não queriam tanto defender uma noção de homogeneidade e de unanimidade das vozes africanas. Pelo contrário, todo filósofo africano que falasse com base na sua herança cultural usava o adjetivo "africano", mas nem por isso queria implicar que a África não tem diversidade. Há diferentes leituras possíveis e devemos ler os textos com grande cautela, compreendendo que pode ter havido reivindicação de uma voz unitária sem que isso signifique negar a diversidade que o continente manifesta. 
Quanto a nós, hoje, acredito que não haja riscos de homogeneizar o pensamento filosófico africano. Vou dar um exemplo: do ponto de vista cultural, a África é diferenciada de muitas formas, há muçulmanos, cristãos, pessoas que não são nem uma nem outra coisa, em termos religiosos. Há hindus africanos, por exemplo, e muitas outras fés para além das três maiores, e quando as pessoas falam a partir desses contextos religiosos, isso não significa que deixem de ser africanos. Se pensarmos no Islã, por exemplo, logo a seguir de Meca, o primeiro lugar para onde a religião seguiu foi a África. A história do Islã africano é tão antiga quanto o próprio Islã, então os muçulmanos africanos pensam legitimamente através de um Islã africano, uma voz muito relevante que foi muitas vezes suprimida e à qual não foi dado o espaço que seria de se esperar. E esse é um sentido da diversidade, porque fala a partir de um contexto que não é necessariamente partilhado por outros africanos que poderão professar outras fés. Se pensarmos nessa perspectiva, a África mantémse diversa de uma maneira muito positiva, enriquecedora, e pode-se dizer que o Islã africano tal como é visto por um estudioso da África ocidental pode não coincidir com o Islã de outros muçulmanos africanos oriundos da tradição islâmica da África Oriental. Essas diferenças são importantes e cruciais para entendermos como a África funciona.

\section{2) Qual foi o papel dos intelectuais africanos do século $X X$ na construção de novas redes de circulação de ideias?}

Os intelectuais africanos começaram mesmo a emergir no século XX, foi no princípio desse século que começamos a reivindicar novamente as nossas vozes, livres do jugo colonial. O falecido Ali Mazrui publicou um livro, pouco antes de morrer, intitulado The African Intelligentsia (A Intelligentsia Africana). Ao refletir sobre os trabalhos dos intelectuais africanos de todo o continente, ele mostra uma pluralidade de vozes refletindo sobre novas transformações sociais, novas ideologias políticas e sobre como essas poderiam ser alavancadas para enraizar a autonomia social, política e cultural da África à medida que saísse do controle colonial. Com a ajuda do trabalho de novos editores e de novos jornais, de fato formou-se uma rede de pensadores refletindo sobre a realidade africana de seu tempo. Podemos pensar a filosofia num 
sentido muito feral, mas é preciso também ter atenção ao conhecimento político. É aqui que a ideia de economia política surge. A própria noção de economia política nasce pelo trabalho de intelectuais pensando na possibilidade de uma autonomia política e econômica e o que é que isso significava em termos concretos, no momento em que a Europa lutava para manter o controle que tinha durante o colonialismo. Pensemos as pessoas como Samir Amin, como Ali Mazrui, como Adjay, eles eram historiadores, cientistas políticos, pessoas que pensavam sobre a África de maneiras diferentes e com um entendimento muito lúcido do funcionamento global no que diz respeito aos interesses econômicos, ao controle político e de como isso tudo está relacionado com a busca da liberdade. Essa rede estabeleceu os elementos de uma teoria que permitisse compreender os obstáculos que barravam o caminho de uma verdadeira libertação dos países que tinham saído do controle do colonialismo.

\section{3) A ancestralidade é muitas vezes considerada um conceito-chave da Filosofia}

\section{Africana, você? Ou o Senhor? concorda com esta visão?}

Concordo totalmente. Porém gostaria de acrescentar que não é apenas uma peculiaridade africana ou pós-colonial. Toda gente se reivindica de uma tradição e quem faz isso constrói a ideia da tradição no reconhecimento de que há uma herança histórica prevalente que define os povos na medida em que cultivam um sentido de identidade histórica. A ancestralidade é sempre uma parte de como escrevemos a história, é uma parte de como escrevemos a identidade, é uma parte de como escrevemos a autonomia. Então, isso não é único da África, mas os filósofos africanos têm o mérito de pensar algo mais visível do que geralmente se pensa. Ou seja, que nossas ideias, na medida em que procuramos defini-las como pertencendo ao continente e como sendo indígenas, apenas podem ser pensadas como tendo sido adquiridas dos antepassados através dos tempos. A tradição oral, por exemplo, dominou a forma como pensamos acerca daquilo que herdamos, porque muitos de nós não tivemos fontes escritas por meio das quais pensar o nosso passado. Uma exceção sendo, claro, a Filosofia Islâmica, porque as bibliotecas em Timbuctu, em Gao, na África Ocidental e em vários outros sítios da África Oriental guardaram muitos documentos escritos em Árabe. Esses são documentos ancestrais, são fontes 
ancestrais que tratam do que é que nós dizemos ter herdado e de como o conhecimento foi transmitido do passado ao presente. A ancestralidade é algo importante, é algo que é de fato central. Ela é a chave da forma como pensamos a nós próprios como representantes dos últimos estágios da progressão histórica. Mas não se trata de algo que é peculiar da África, é como as pessoas escrevem as suas identidades em todo o lado, é um valor global. A única diferença é que por vezes nem todas as nossas fontes ancestrais são disponíveis através de documentos que sejam comuns a todos, porque algumas dessas fontes são orais e conservadas na memória.

\section{4) Como é que podemos identificar, no discurso dos intelectuais e pensadores africanos, uma ruptura em face aos temas, conceitos e categorias do pensamento europeu?}

Sendo que pensamos como sujeitos históricos, nós, filósofos e intelectuais africanos, em geral, deveríamos pensar como tendo escrito nossas próprias histórias através do colonialismo. O colonialismo deixou uma marca, é algo que nós não negamos, é algo que nos afetou, algo que interrompeu o nosso pensamento indígena acerca do Eu (self). Até mesmo herdamos algumas categorias da Europa, não faz mal, não acho que deveríamos chorar por causa disso, seria uma maneira falsa de olhar para o que é que a história significa de verdade. Herdamos algumas coisas, mas temos as nossas também, na forma de como pensamos a nossa liberdade, como pensamos a nossa tradição, como pensamos a nossa cultura, como pensamos o lugar na história onde estamos hoje. Há coisas que são específicas da África e que poderão não existir em outros lugares, porque a história corre por linhas por vezes muito diferentes, por vezes muito parecidas. Há temas que são próprios da África, o tema da liberdade, por exemplo. A forma como temos pensado a liberdade, a forma como temos trazido à mesa, perante os olhos de todos, a ideia de liberdade, tem a ver com o fato de termos sido outrora dominados por forças e tradições exteriores. Pensemos na questão da identidade, que nos têm preocupado de uma forma muito intensa, mas não é uma coisa negativa. Tinha que ser assim, porque estávamos num movimento de reivindicação de nós mesmos, de reivindicação da nossa tradição, de reivindicação do 
nosso lugar no âmbito da interpenetração de culturas que as tecnologias contemporâneas — viagens, comunicações, etc. — trouxeram. São formas de pensar a identidade que descrevem ou respondem o desejo das pessoas de serem elas próprias, mesmo enquanto encontram o outro, enquanto encontram o estranho. Liberdade, identidade, formas diferentes de pensar o Eu (self) e o seu funcionamento são ocasiões importantes para encontrar novas categorias para pensar o mundo, para encontrar conceitos de um outro tipo que emergem de tradições diferentes à medida que as pessoas tomam consciência umas das outras e dão reconhecimento às suas diferentes trajetórias históricas. Então, há uma ruptura, claro que há. Mas, apenas de forma muito mitológica, uma ruptura deve ser vista como oposição completa a todos aqueles com quem alguma vez se teve contato. É isso que o pluralismo envolve sempre. Haverá posições que são opostas umas às outras, por exemplo, nossa demanda sendo sempre em oposição com a demanda de todos aqueles que procuram dominar. Portanto, a ideia de liberdade é uma ideia de oposição, mas isso não significa que estejamos sempre e permanentemente contrários uns aos outros, porque a própria ideia de perspectivas globais é de proporcionar muitas vias alternativas de conhecimento e de prática à medida que cruzamos com outras pessoas de todo o mundo.

\section{5) Como descreveria os traços essenciais do legado epistemológico dos} pensadores africanos, em particular na sua relevância para o pós-colonialismo e a descolonização?

O conhecimento é uma coisa bastante interessante. Aquilo que temos vindo a dizer na África é que a forma como exprimimos nosso pensamento não precisa ser idêntica à forma como todos os outros exprimem o seu. Temos fontes de pensamento filosófico que nos são únicas, e que nos proporcionam atitudes diferentes para conhecer as coisas. Então aquilo que eu considero ser bom ou aquilo que sei estar certo deve refletir alguns dos legados que nos são próprios como povo que tem a sua própria trajetória no tempo. O conhecimento move quase tudo aquilo que os humanos fazem. No âmbito da saúde, por exemplo, o que é que significa estar saudável, estar doente? São coisas que não são universais, que são específicas a cada 
cultura. Aquilo que é considerado um transtorno mental na Europa pode não ser necessariamente considerado um transtorno mental noutros lados. A ideia do que é a sanidade, do que é a doença, reflete a forma como as pessoas conhecem o mundo. E todas essas diferenças epistemológicas levantam a questão de como pensar as coisas de forma diferente. Por vezes, muito me impressiona ver o quanto são medicadas as pessoas nos Estados Unidos, onde vivo e trabalho. Como as crianças que se manifestam além de um certo grau de expectativa são consideradas não saudáveis e lhes é administrado todo tipo de medicação, porque de repente são classificadas como tendo transtorno do déficit de atenção com hiperatividade (TDAH). Tudo isso precisa de abordagens baseadas nas nossas ideias do que é saber, do que está certo, do que é saudável. Essas são questões e heranças epistemológicas que são diferentes noutros lugares do mundo. Em particular, poderíamos dizer que os legados epistemológicos africanos vão além dos textos escritos e incluem os textos orais. Hoje, aliás, com as novas tecnologias, a ideia de que o texto escrito é a única referência disponível quando se trata de tomar decisões está ficando obsoleta até no próprio ocidente. É assim que voltamos à forma como as pessoas agem, às suas práticas. Esse é o legado que os intelectuais oriundos da África deveriam enfatizar e comunicar ao mundo: que a narrativa escrita não é a única referência acerca do funcionamento do mundo.

\section{6) Tendo em consideração os questionamentos vindos das regiões periféricas} (fora do centro, fora da Europa), quais são, em sua opinião, as contribuições mais relevantes e originais da Filosofia Africana?

Isso quase que me leva a considerar o ditado, muito debatido, do falecido Léopol Sédar Senghor [“A emoção é negra como a razão é helênica”, NdR], e a pensar não só que a razão funciona de muitas maneiras, mas que é apenas uma das formas com que as pessoas conhecem o mundo que as envolve. Olhar o mundo a partir de um senso de relacionamento com o mundo e com os outros que seja mais participativo e mais abrangente é uma forma legítima de conhecimento. A partir daí, podemos desenvolver abordagens participativas no mundo, na maneira como as pessoas se organizam e trabalham de forma comunitária antes de depender de 
posturas individualistas que são muitas vezes dominantes no ocidente. Os filósofos africanos estão oferecendo alternativas muito válidas aos modos de funcionamento que são mais comuns na Europa. Pensemos, por exemplo, a própria ideia de verdade segundo a análise de Kwasi Wiredu, que considero o filósofo africano mais destacado de hoje. Wiredu defendeu que a ideia de verdade tal como é pensada na tradição filosófica ocidental é uma ideia estúpida. A verdade em termo de correspondência é uma coisa absolutamente impossível, um desejo mítico que nunca será atingido do ponto de vista experiencial. Seria mais aceitável considerar o conhecimento como algo comunitário, em vez de pensar o conhecimento como a elevação do indivíduo cujas experiências e percepções são vistas como alicerce de uma correspondência entre mente e realidade. Esses são mitos, mas são os mitos que têm controlado e impulsionado as perspectivas filosóficas ocidentais, o que produziu mais problemas do que resolveu. O trabalho de Wiredu é um exemplo brilhante de como pensadores africanos podem contribuir ao debate filosófico e dialogar uns com os outros para além da separação entre analíticos e continentais.

\section{7) Quais são, na sua opinião, as condições em que pode haver um diálogo entre pensadores africanos e pensadores europeus ou de outros continentes, em que os primeiros não sejam mais objetos, mas sujeitos em sentido pleno?}

A meu ver, precisamos expandir a ideia da diversidade do conhecimento a nível global. Ao fazermos isso, poderemos ser mais abertos a tradições de conhecimentos oriundas de outros lugares, mas isso implica que tenhamos formas de disseminação, como revistas, etc., que sejam novas e, por assim dizer, mais liberais, para que possamos difundir e trocar conhecimento pelo globo afora. Precisamos estabelecer canais em que o conhecimento de fora da Europa possa obter reconhecimento. Eu, para dar um exemplo, sou membro do comitê editorial de uma coleção da Indiana University Press chamada World Philosophies. O objetivo da série é promover o diálogo entre tradições filosóficas externas à Europa e à América do Norte e as perspectivas filosóficas ocidentais. Publicamos textos muito bons, de autores provenientes do Sudeste Asiático, da Índia, da África, mas a nossa atenção está sobretudo nos pensadores cujos trabalhos oferecem formas alternativas de ver problemas filosóficos 
tanto novos como antigos. Publicar novas coleções de textos e fundar novas revistas que sejam abertas a fontes filosóficas de outros lugares do mundo, é esse gênero de iniciativas que irá promover o diálogo.

\section{8) O racismo pode tomar muitas formas. Como poderemos combater o} racismo epistemológico?

É uma pergunta muito difícil (risadas)! Um racista vai continuar racista, como é que se convence um racista a abandonar suas posições? É claro que tudo o que você pode fazer é apresentar argumentos alternativos que tornam a sua posição inaceitável. Depois você tem que deixá-lo decidir se abandona ou não a sua posição. De qualquer forma, o racismo é em primeiro lugar e sobretudo uma questão de conhecimento. Quando os pensadores europeus acham que apenas eles sabem o que é verdade, o que é bom, o que está certo, é isso que estamos tentando combater. Tudo o que europeus e norte-americanos sabem foi a partir de suas próprias perspectivas, não é universal. Desuniversalizar, fazer com que Europa e América do Norte percebam que suas posições são particulares e devidas às suas próprias perspectivas e não universais, tomara que isso crie as condições de um diálogo em que cada posição é considerada apenas como uma das alternativas e que nenhuma delas estabelece de forma necessária a maneira como o mundo deve ser conhecido.

9) Nos últimos anos, o Brasil adotou várias leis para promover a igualdade social entre brancos e negros, como medida de discriminação positiva como as cotas raciais. Qual é a sua visão da questão racial no Brasil?

É um fenômeno muito complexo. É mais complexo que em muitos outros lugares do mundo, porque há mais categorias de diferenciação racial de quanto seja possível perceber. Penso que devemos encorajar toda medida de promoção da igualdade entre as diferentes categorias raciais que caracterizam a sociedade brasileira. Como forma de promover o acesso por parte de grupos diferentes até lá subrepresentados, as cotas são uma coisa muito boa que deve ser apoiada, pelo menos 
são uma boa maneira de começar. E começa-se precisamente por exigir que grupos sub-representados possam ter uma chance de emancipação e de reconhecimento não apenas em nível da ideologia e dos slogans políticos, mas em termos práticos, ou seja, fazendo com que essas pessoas sejam parte das instituições que movem a sociedade. As cotas são uma boa ideia e devem ser defendidas, claro que têm suas controvérsias, como acontece com a ação afirmativa nos Estados Unidos. Mesmo não sendo perfeitas, que nestes assuntos nunca há perfeição, são pelo menos uma maneira concreta de orientar os processos políticos em direção de um maior reconhecimento e de uma sociedade mais inclusiva. 